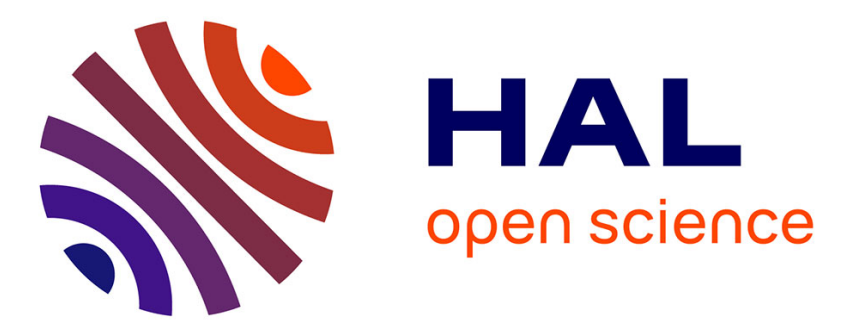

\title{
Maternal presence influences vocal development in the Japanese quail ( Coturnix c. japonica )
}

Lucie Desmedt, Isabelle George, Aïcha Mohamed Benkada, Maxime Hervé, Thierry Aubin, Sébastien Derégnaucourt, Sophie Lumineau

\section{- To cite this version:}

Lucie Desmedt, Isabelle George, Aïcha Mohamed Benkada, Maxime Hervé, Thierry Aubin, et al.. Maternal presence influences vocal development in the Japanese quail (Coturnix c. japonica ). Ethology, 2020, 126 (5), pp.553-562. 10.1111/eth.13007 . hal-02474536

\section{HAL Id: hal-02474536 https://hal-univ-rennes1.archives-ouvertes.fr/hal-02474536}

Submitted on 19 Oct 2020

HAL is a multi-disciplinary open access archive for the deposit and dissemination of scientific research documents, whether they are published or not. The documents may come from teaching and research institutions in France or abroad, or from public or private research centers.
L'archive ouverte pluridisciplinaire HAL, est destinée au dépôt et à la diffusion de documents scientifiques de niveau recherche, publiés ou non, émanant des établissements d'enseignement et de recherche français ou étrangers, des laboratoires publics ou privés. 
Lucie Desmedt, Isabelle George, Aïcha Mohamed Benkada, Maxime Hervé, Thierry Aubin, et al.. Maternal presence influences vocal development in the Japanese quail ( Coturnix c. japonica ). Ethology, Wiley, 2020, 126 (5), pp.553-562. 〈10.1111/eth.13007〉. 〈hal-02474536〉

Authors' pre-print

Editor's version available at the following:

https://doi.org/10.1111/eth.13007

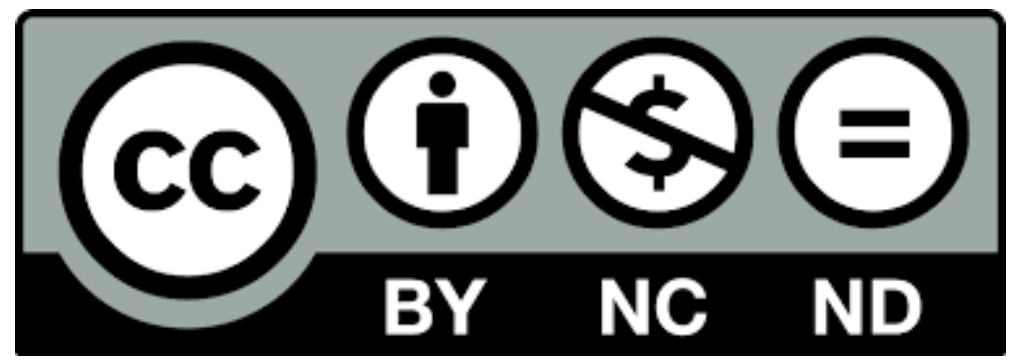


1 Short title: Maternal influences on calls in quail

2 Title: Maternal presence influences vocal development in the Japanese quail (Coturnix $c$.

$3 \quad$ japonica)

4 Authors: Lucie DESMEDT ${ }^{\mathrm{a}}$, Isabelle GEORGE ${ }^{\mathrm{a}}$, Aïcha MOHAMED BENKADA ${ }^{\mathrm{a},+}$, Maxime HERVÉ

5 Thierry AUBIN", Sébastien DERÉGNAUCOURT ${ }^{\mathrm{d}, \mathrm{e}, \# \text {, Sophie LUMINEAU }}{ }^{\mathrm{a}, \#, *}$

6 a Univ Rennes, Normandie Univ, CNRS, EthoS (Éthologie animale et humaine) - UMR 6552, F-35000 Rennes, France

7 b Univ Rennes, INRA, Agrocampus Ouest, IGEPP_UMR-A 1349, F-35000 Rennes, France

$8 \quad$ c Université Paris Sud, UMR 9197 NeuroPSI-CNRS, F-91405 Orsay, France

9 d Université Paris Lumières, Université Paris Nanterre, EA 3456 LECD, F-92001 Nanterre, France

e Institut Universitaire de France, France

${ }^{\dagger}$ Current address: CNRS, INRA, Univ Tours, Physiologie de la Reproduction et des Comportements, UMR7247-85, F-37380

${ }^{\#}$ Equal contributions

* Corresponding author : Campus de Beaulieu, 263 av. du Général Leclerc, Bâtiment 25 - 35042 Rennes Cédex, France. E-

\section{Acknowledgments}

We are grateful to Emmanuel De Margerie for his contribution in writing the Matlab routine and we would like to thank Céline Nicolle for the animal care. 


\section{Abstract}

Social influences on vocal development of young birds have been widely studied in oscine songbirds who learn to sing by vocal imitation of conspecifics, mainly male adults. In contrast, vocal development of non-vocal learners such as Galliformes is considered as being under strong genetic influence and independent of the social environment. In this study, we investigated the role of the mother on the vocal development of young Japanese quail (Coturnix coturnix japonica). We compared the vocal development of mothered and non-mothered chicks during the first 21 days of life. We analysed the structural changes of two vocalisations: a) the rally call, emitted during long distance communication and in stressful situations, b) the contact call, emitted during short distance communication when chicks are in visual and/or auditory contact with congeners. We showed that temporal and spectral structures of the two types of calls changed during development and differed between mothered and non-mothered chicks. These results demonstrate that maternal presence influences the vocal development of the young in the Japanese quail. Even if the adaptive value of such changes was not assessed, these results highlight that plasticity of vocalisations in species considered as non-vocal learners has been underestimated.

Keywords: mother, vocal learning, vocalisations, precocial bird

\section{INTRODUCTION}

Vocal learning is the ability to imitate sounds from the acoustic environment. This prerequisite to language development in humans is a rare trait in the animal kingdom. In birds, it has been described in oscine songbirds, parrots and hummingbirds (Baptista \& Petrinovich, 1984; Thorpe, 1958). For example, in several species of oscine songbirds, young individuals learn to sing by imitating conspecifics, mainly adults. An absence of auditory models leads to the production of impoverished or abnormal songs (Passeriformes: Peter Marler, Mundinger, Waser, \& Lutjen, 1972, Price, 1979; Psittaciformes: Brittan-Powell, Dooling, \& Farabaugh, 1997; Apodiformes: Jarvis, 2004). Early maternal effects of call exposure studied in Superb Fairy-wren (Malurus cyaneus) embryos were 
found to shape the learned begging call at hatch, which was demonstrated with cross-fostering experiments (Colombelli-Négrel et al., 2012) and with in ovo measurement of response to calls and song (Colombelli-Negrel, Hauber, \& Kleindorfer, 2014; Colombelli-Négrel \& Kleindorfer, 2017; Kleindorfer, Evans, Hauber, \& Colombelli-Négrel, 2018).

In the so-called non-vocal learner bird species, experiments of auditory deprivation showed little or no effects on the ontogeny of vocalisations (Galliformes: Konishi, 1963; Columbiformes: Nottebohm \& Nottebohm, 1971; Passeriformes: Kroodsma \& Konishi, 1991). This led to the conclusion that vocalisations of non-vocal learners are under strong genetic influence.

However, several studies have reported vocal changes in both juvenile and adult birds of non-vocal learner species. In adults, temporal and spectral variations in calls' structure has been observed in the male loons Gavia immer after a change of territory (Gaviiformes: Walcott, Mager, \& Piper, 2006), and across seasons in the Gray Partridge Perdrix perdrix (Galliformes: Rotella \& Ratti, 1988). Vocal changes during vocal development have also been described in the Pied avocet Recurvirostra avosetta (Charadriformes: Adret, 2012), the Japanese quail Coturnix coturnix japonica (Galliformes: Derégnaucourt, Saar, \& Gahr, 2009; Guyomarc'h \& Guyomarc'h, 1996), the Collared dove Streptopelia Decaocto (Columbiformes: Ballintijn \& Ten Cate, 1997) and the Grey crowned crane Balearica regulorum gibbericep (Gruiformes: Budde, 2001). To our knowledge, no study has explored the social influences on vocal development in young birds of a non-vocal learner species. However, it has recently demonstrated that the vocalisations of marmoset infants (Callithrix jacchus), non-human primates traditionally considered as non-vocal learner species, are sensitive to parental feedback (Takahashi et al., 2015).

Many studies based on a maternal deprivation paradigm in quails have already highlighted the nongenetic role of the mother on the young’s social motivation (Bertin \& Richard-Yris, 2005), emotivity (Pittet, Le Bot, Houdelier, Richard-Yris, \& Lumineau, 2013), spatial skills (de Margerie et al., 2013) and rhythmicity (Formanek, Richard-Yris, Houdelier, \& Lumineau, 2009). In our study, we did not examine vocal similarity between mother and chicks, but we aim to explore the maternal influences on vocal development in chicks of the Japanese quail, a species traditionally considered as a non-vocal 
learner. In this species, parental care after laying is exclusively carried out by the mother over a relatively short period of time (Orcutt \& Orcutt, 1976). Maternal behaviour can be easily induced via an adoption procedure, avoiding genetic influences (Richard-Yris, Michel, \& Bertin, 2005). Given the behavioural plasticity of chicks, we thus expected to find maternal influences on vocal development too. We also tested the possible existence of a horizontal transmission of vocalizations between chicks raised in a same pair. Indeed, young could influence each other regardless of the presence or the absence of the mother. In order to test this hypothesis we explored chicks' acoustic similarity.

\section{MATERIALS \& METHODS}

Ethical note

All experiments were approved by the departmental direction of veterinary services (Ille-et-Vilaine, France, permit number 005283) and were performed in accordance with the European Communities Council Directive of 22th September 2010 (2010/63/EU). The breeding procedure was approved by the regional ethics committee (agreement number: R-2011-SLU-02).

\section{Subjects and maintenance condition}

The birds (adults and chicks) used in this study were Japanese quail (Coturnix c. japonica) of a broiler line. They were provided by an industrial farm (Les cailles de Chanteloup, Corps-Nuds, France).

Three weeks before the start of the experiment, 20 adult females (4.5 months old) were placed in individual metal cages (52 x 40 x $35 \mathrm{~cm}$ ) equipped with a feeder and a drinking trough. Opaque walls prevented any visual contact between individuals. 

The chicks came from eggs artificially incubated (Brinsea, OVA-Easy Advance Series II) in the laboratory during 17 days. After hatching, chicks were weighed and identified with a coloured and numbered ring on each leg. Then, groups of 20 individuals were placed in large cages $(94 \times 46 \times 30$ $\mathrm{cm}$ ) equipped with a heater $\left(37 \pm 1^{\circ} \mathrm{C}\right)$, a feeder and a drinking trough. On the evening of the hatching day (D1), chicks were moved in a mothering room and randomly assigned to an experimental group: mothered (M-group) or non-mothered (NM-group). The mothered chicks (20 pairs) were raised by an adoptive mother, while the non-mothered chicks (15 pairs) were kept with a heating lamp. The chicks within each pair were not genetically related.

All the birds were in the same room, but pairs of chicks could not see each other. Food and water were provided ad libitum throughout the duration of the experiment. The mothering room was kept at $22 \pm 1$ ${ }^{\circ}$ C, with LD 10:14 cycle.

As quail chicks cannot be sexed by visual inspection before they are four weeks old (Baer, Lansford, \& Cheng, 2015), chicks were randomly attributed to one of each group without knowing their sex. Sex was determined after the end of the experiment when the birds were 4 weeks old. However, the sex ratio did not differ between the mothered (10 females and 20 males) and the non-mothered (17 females and 13 males) group (Chi-square test: $X^{2}=2.42, d f=1, P=0.12$ ).

The mothered and the non-mothered chicks' growth (body mass) differed during development (LMM Wald test, groups $x$ days: $X^{2}=6.0146, d f=1, P=0.01419$ ), with faster growth for the non-mothered chicks (Means and standard errors are presented in Table. S1). This result is in agreement with previous studies (Pittet et al., 2013).

Experimental procedure

Maternal induction 
The procedure used in this study was previously described and has demonstrated that tactile and vocal stimulations between the female and the young at night favour the emergence of maternal behaviour (Richard-Yris et al., 2005).

Three days before the induction of the maternal behaviour, a rearing box $(19 \times 19 \times 19 \mathrm{~cm})$ was introduced in every cage of the mothering room. On the day of hatching, each female was locked in the rearing box one hour before the end of the photoperiod. Two one-day old chicks were then placed with each female and stayed there overnight. The chicks of the non-mothered group were also placed in pairs in a rearing box equipped with a heating lamp.

The boxes were opened the next morning to check the expression of maternal behaviour by females. Mothers with rejection or aggressive behaviours toward the chicks $(n=5)$ were excluded from the study. After exclusion, mothered and non-mothered groups were both composed of 30 chicks.

Mothers and heating lamps were removed from the cages on the evening of the 11th day, at the age at which the chicks disperse in the wild (Mills, Crawford, Domjan, \& Faure, 1997; Orcutt \& Orcutt, 1976). Pairs of chicks stayed in their respective cages until the end of the experiment (D21).

\section{Recording of vocalisations}

The vocalisations of the chicks were recorded every day between D3 and D21 of life. Due to a technical problem, the vocalisations of D9 were not recorded.

Each day of recording, 2 chicks of the same pair were removed carefully from their life cage, transported together to the recording room, and placed individually in a wooden cage $(82 \times 61 \times 36$ $\mathrm{cm})$. The cages were placed in 2 sound-attenuating rooms $(190 \times 93$ x $243 \mathrm{~cm})$.

After 3.5 min of recording in social isolation, the two chicks were brought together in a third empty cage (90 x $48 \times 53 \mathrm{~cm}$ ), also placed in a sound-attenuating room. The two chicks were placed on opposite side of the cage. Two wire separations (43 x $27 \mathrm{~cm}$, separated by $17 \mathrm{~cm}$ ) prevented tactile contacts between them, while allowing visual and vocal interactions. This separation allowed us to 
then distinguish the calls emitted by the 2 chicks. The vocal interactions during this stage were recorded for $3.5 \mathrm{~min}$. The chicks were then brought back together in their life cage.

These two experimental situations made it possible to record two types of vocalisations, rally calls and contacts calls.

The order in which every pair of chicks was recorded was randomised each day.

Vocalisations were recorded using the Sound Analysis Pro (SAP) software (Tchernichovski, Lints, Derégnaucourt, Cimenser, \& Mitra, 2004). The program was run on a PC equipped with an AudioBox PreSonus 1818VSL interface (sampling frequency: $44.1 \mathrm{kHz}$ ) connected with omnidirectional microphones (AKG C417PP, frequency response $30 \mathrm{~Hz}-20 \mathrm{kHz} \pm 5 \mathrm{~dB}$ ). One microphone was positioned in the centre of the cage used for the social isolation phase (at $30 \mathrm{~cm}$ from the floor) and two microphones were positioned on each side of the cage used for the reunion phase (at $16 \mathrm{~cm}$ from the floor).

\section{Sound analysis}

Acoustic analyses were made with SAP signal processing software (Tchernichovski et al., 2004), and the similarity analyses with the ANA software (Richard, 1991).

\section{Calls structure}

Good quality calls (no overlapping with noise due to the bird movements in the cage or with calls from the other chick during the reunion phase) were selected by visual inspection of spectrograms.

During the isolation phase, we sampled the first thirty vocalisations emitted by each individual for each day of recording. After an auditory and visual inspection of the spectrogram, each vocalisation was classified according to already published descriptions of the vocal repertoire of the Japanese quail (Guyomarc'h \& Guyomarc'h, 1996). We focused our analysis on the rally calls (Fig. 1A), which are vocalisations of strong social value and further emitted by chicks when losing visual contact with 
conspecifics. Rally calls represented $90 \%$ of the sampled calls (sampled calls, $n=30276$; rally calls, $n$ $=27464)$.

For the reunion phase, we focused our analysis on contact calls, one of the main vocalisations expressed during social interactions (Fig. 1B). Calls from the microphone on the left side of the cage ( $n=1336$ calls) were manually selected from a visual inspection of the spectrogram to define the beginning to the end of each call. A routine on Matlab was then used to automatically sample the same calls in the recordings coming from the microphone placed on the right side of the cage. By comparing the amplitude of the sampled calls on the two channels, each vocalisation could be attributed to one of the individual chicks.

We used the SAP software to extract automatically the duration, the mean frequency, the Wiener entropy and the frequency modulation (FM) of the rally calls. For the contact calls, the maximal frequency and the minimal frequency were measured by clicking on the sonogram using SAP. These values were used to measure the frequency bandwidth (see Table. 1 for parameters detail).

\section{Similarity analyses}

In order to explore the influence of maternal deprivation on the intra-pair (chicks raised in the same life cage) and inter-pair (chicks raised in different life cage, but of the same group $\mathrm{M}$ or NM) acoustic similarity, one contact call was selected randomly for each chick and each day from D3 to D21. A total of 381 contact calls were used for this analysis. Nevertheless, for some individuals we have not always been able to select a call per day because no contact calls were emitted during the recording.

We used a similarity index that has been used successfully in other species (birds: Adret-Hausberger, 1983; cetaceans: Miller \& Bain, 2000; primates: Lemasson, Gautier, \& Hausberger, 2003), using ANA software (Richard, 1991). For each pairwise comparison, the program compared the frequency contour of the sonograms and automatically looked for the best superposition along the frequency and duration axes providing a ratio of 'overlap' between both contours. 
Thus, for each day of development and each chicks, we calculated an intra-pair similarity index and an inter-pair similarity index. Inter-pair similarity index corresponded to the average of inter-pair values obtained between individuals of the same sex and raised in the same pair composition (pair of samesex chicks or not). For example, for a mothered male raised in a mixed pair (with a female), we calculated the average of similarity index obtained between this male and all the other mothered males raised in a mixed pair. This approach made it possible to obtain inter-pair similarity indices independent of sex effects.

\section{Statistical analysis}

Statistical analyses were performed using the software R v.3.5.1 (R Core Team, 2016).

To test the influence of mothering on the acoustic parameters of chicks' calls we used Wald tests applied on a linear mixed model (functions Imer from package Ime4 Bates, Mächler, Bolker, \& Walker, 2014 and Anova() from package car Fox \& Weisberg, 2010). When the residuals did not respect the conditions of application of the model, data were transformed with the square root function. The fixed factors were the experimental group (mothered or non-mothered), the day of recording (from D3 to D21; with scale function of $\mathrm{R}$ ) and the sex of the individual. The random factors were birds and pairs identity, and the pair composition.

We analysed the similarity scores using Wald tests applied on a generalised linear mixed model with a logit link and a binomial distribution (functions glmmPQL from package MASS Ripley et al., 2018 and Anova() as above). Fixed effects included experimental groups (mothered or non-mothered), the day of recording (from D3 to D21), the sex of the individual and the comparison level (intra- or inter-pair). Bird’s identity and the pair composition were included as random factors.

All models included second-order interaction terms. The model estimates are presented in Table. S2, and the slopes estimates in Table. S3. The threshold of significance was 0.05. 
Developmental changes of rally calls

Both temporal and frequency parameters of rally calls changed significantly during development. We observed a decrease of call duration and mean frequency with time, and an increase of frequency modulation and Wiener entropy, for both mothered and non-mothered chicks (Fig. 2; Table. 2, LMM: postnatal day; see Fig. S1 for individual curves).

We observed significant developmental differences between mothered and non-mothered chicks for the four acoustic parameters (Table. 2, LMM: group*postnatal day). Overall, the development of the rally calls was faster in the mothered chicks than in the non-mothered ones (Table. S3, steeper slopes for the 4 acoustic parameters; Table. 2, LMM: group*postnatal day). The differences between rally calls' structure of mothered and non-mothered chicks were not the same during and after the mothering period. During the mothering period (first eleven days of life), the mothered chicks produced higher-pitched calls with a lower Wiener entropy (Fig. 2C and 2D). After mothering ended, differences in mean frequency disappeared but mothered chicks emitted shorter calls, with a higher FM and Wiener entropy (Fig. 2A, 2B and 2D).

We also observed differences between females and males (Fig. S2; Table. 2, LMM: sex*postnatal day and sex), independently of the experimental group (Table. 2, LMM: group*sex). Females produced rally calls with a higher FM and a higher mean frequency than males' calls. Moreover, whereas the call duration of females increased along development, the duration of males' calls decreased. Females' calls also showed a slower decrease for the mean frequency (Table. S3). 
The acoustic structure of contact calls also changed significantly during development, with an overall decrease in duration, in maximum frequency and in frequency bandwidth (Table. 2, LMM: postnatal day).

We observed significant developmental differences between mothered and non-mothered chicks (Table. 2, LMM: group*postnatal day). During the mothering period, the two groups differed in frequency bandwidth and maximum frequency (Fig. 3B and 3C). Mothered chicks produced contact calls with a lower maximal frequency and a narrower frequency bandwidth than the non-mothered chicks (Table. 2, LMM: group*postnatal day). After separation (D12), only the duration differed between the two groups, with shorter contact calls in mothered chicks (Fig. 3A).

Overall, mothered chicks' calls showed a faster development of the temporal parameters (Table. S3, steeper slope) and a slower development of frequency parameters (Table. S3, lower slope) than nonmothered chicks’ calls (Table. 2, LMM: group*postnatal day).

We found differences in the development of females' and males' contact calls (Fig. S3; Table. 2, LMM: sex*postnatal day), independently of the experimental group (Table. 2, LMM: group*sex). Frequency parameters and call duration decreased slower in females than in males (Table. S3).

\section{Acoustic similarity between contact calls of chicks' pairs}

There was no interaction between the experimental group and the age (Table. 2, GLMM: group*postnatal day) and between the experimental group and the comparison level (inter- and intrasimilarity; Table. 2, GLMM: group*comparison level). We did not find any effect of mothering on vocal similarity (Table. 2, GLMM: group).

However, there was a significant difference between inter- and intra- pair similarity with the stage of development (Table. 2, GLMM: comparison level*postnatal day). Intra-pair similarity was always 
greater than inter-pair similarity but it decreased along development whereas inter-pair similarity remained stable (Fig. 3D; Table. S3).

The sex of the chicks also had an influence on the changes in the similarity index with development (Fig. S3; Table. 2, GLMM: sex*postnatal day). There was a decrease in the similarity index of the males while the similarity index of females remained stable (Table. S3). Sex did not interact with the experimental group (Table. 2, GLMM: group*sex), nor with the comparison level (Table. 2, GLMM: comparison level*sex).

\section{DISCUSSION}

Our results highlight the role of social interactions on the vocal development of Japanese quails. The differences in acoustic structures observed between mothered and non-mothered chicks demonstrate that the presence of the mother influences the vocal development of its young. This finding challenges the idea that in birds traditionally classified as non-vocal learners, vocal development of young is independent of the auditory and social environments.

It is very likely that the mother induced vocal changes through both short- and long-term influences on the behavioural phenotype of her young. In Japanese quail, mothered birds are more sensitive to social separation at young age (Bertin \& Richard-Yris, 2005) and adulthood (Pittet et al., 2013). Thus, the context of social isolation in our study may have led to an increased level of stress in mothered chicks. Since stressful situations have been shown to be accompanied by spectral changes in calls of many mammals (Briefer, 2012; Zhang \& Ghazanfar, 2016) and more recently in a bird species (Perez et al., 2012), an increased level of stress may explain the production of rally calls higher in frequency and with a lower Wiener Entropy in mothered chicks during the mothering period. In Galliform species, social isolation is accompanied by the production of rally calls (Guyomarc'h \& Guyomarc'h, 1996) but our study is the first one to explore the existence of structural variations in these calls in response to a stressful situation. Vocal changes related to emotional states may be due to physiological changes 
or the release of hormones such as glucocorticoids (Perez et al., 2016; Riters, 2012). Other hormones such as testosterone have also been shown to influence the vocalisation pattern in Galliformes (Beani, Briganti, Campanella, \& LUPO, 2000; P. Marler, Kreith, \& Willis, 1962).

The emotional and motivational state of the birds during the reunion phase is more complex to explain. Indeed, the impossibility of any physical contact between the two chicks might have induced a state of frustration or emotional confusion. Previous studies have shown that motherless chicks are less socially motivated and more aggressive (Bertin \& Richard-Yris, 2005). Thus, in our study, production of high-frequency calls by non-mothered chicks could be associated with a higher emotional state (higher level of stress) following in the same way the structural motivational code conceptualised by Morton (Morton, 1982) for bird vocalisations. Indeed, if, for the non-mothered chicks, the reunion was complete (because they met their unique life partner), for the mothered chicks it was partial only because they met their same-age congener but not their mother. Maybe in the case of a complete reunion, mothered chicks would produce high-frequency calls. Moreover, in addition to the acute context-related stress during recordings, maternal deprivation may have created a chronic stress that influenced the developmental trajectory of non-mothered chicks' vocalisations. Additional experiments including video recordings and physiological measurements would be required to document the influence of the emotional state on the acoustic structure of quail's vocalisations.

The mother, by her presence, could also influence the growth of her chicks, and thus the maturation of their vocal apparatus. Several studies have demonstrated a negative correlation between body size and vocal frequency (e.g. Chabert et al., 2015; Patel, Mulder, \& Cardoso, 2010). In our study, we found that the mothered chicks had slower growth than the non-mothered chicks. These results could explain the production of higher-frequency calls at the beginning of the development in the mothered chicks. However, since the mothered chicks produced lower-frequency contact calls, the contact calls' structure does not seem to support this hypothesis. A thorough monitoring of the growth during chick development would be necessary to test whether some vocal changes could correlate with differences in body mass or size. 
Vocal differences observed in our study, between mothered and non-mothered chicks, may have a

332 functional aspect. Vocalisations can transmit information about the needs of young (Klenova, 2015;

333 Leonard \& Horn, 2001) and they can affect maternal responses accordingly (Chabert et al., 2015;

334 Perez et al., 2016). Vocalisations of the mothered chicks are likely to be better adapted to the mother-

335 young interactions than those of the non-mothered chicks but playback experiments would be required to test this hypothesis.

The mother could also influence the vocal development of her young through imitation like in songbirds. Young oscines learn their songs by memorising and imitating those produced by conspecific adults (Brainard \& Doupe, 2002). Social isolation leads to the production of abnormal songs in several oscine species (Chaiken, Gentner, \& Hulse, 1997; Price, 1979). A comparative analysis of the maternal and the juvenile vocalisations could be made to test this hypothesis.

Our results also suggest that a potential imitation could occur horizontally between the two chicks, in both the mothered and the non-mothered groups. Indeed, the acoustic similarity index showed a greater intra-pair similarity compared to the inter-pair similarity, regardless of the presence or absence of the mother. Chicks from the same pair may have stimulated and imitated each other. In songbirds like European starlings and zebra finches, young influence each other either in the absence or in presence of a conspecific adult (Chaiken et al., 1997; Derégnaucourt \& Gahr, 2013; Poirier et al., 2004; Volman \& Khanna, 1995). The decrease in intra-pair acoustical similarity during development may reflect an individualisation of contact calls after separation from the mother.

In conclusion, our study shows, for the first time, non-genetic maternal influences on vocal development in the Japanese quail, a bird species with a vocal repertoire composed of different calls whose structure has been considered for a long time to be insensitive to social influences. In line with recent research on vocal development in non-human primates (Lemasson, Ouattara, Petit, \&

354 Zuberbühler, 2011; Takahashi et al., 2015), our study is a strong invitation to revisit the traditional dichotomy between vocal learners and non-vocal learners species. 


\section{Supplementary material}

Data related to this paper are available from the Dryad Digital Repository: https://doi.org/10.6084/m9.figshare.8241326.v1. Codes for statistics are available from Dryad Digital Repository: https://doi.org/10.6084/m9.figshare.10321517.v1.

\section{References}

Adret-Hausberger, M. (1983). Variations dialectales des sifflements de l'Etourneau sansonnet (Sturnus vulgaris) sedentaire en Bretagne. Zeitschrift Für Tierpsychologie, 62(1), 55-71. https://doi.org/10.1111/j.1439-0310.1983.tb02141.x

Adret, P. (2012). Call development in captive-reared Pied Avocets, Recurvirostra avosetta. Journal of Ornithology, 153(2), 535-546. https://doi.org/10.1007/s10336-011-0774-2

Baer, J., Lansford, R., \& Cheng, K. (2015). Chapter 22 - Japanese Quail as a Laboratory Animal Model. In Laboratory Animal Medicine: Third Edition (pp. 1087-1108). Academic Press. https://doi.org/10.1016/B978-0-12-409527-4.00022-5

Ballintijn, M. R., \& Ten Cate, C. (1997). Vocal Development and Its Differentiation in a NonSongbird: the Collared Dove (Streptopelia Decaocto). Behaviour, 134(7), 595-621. https://doi.org/10.1163/156853997X00548

Baptista, L. F., \& Petrinovich, L. (1984). Social interaction, sensitive phases and the song template hypothesis in the white-crowned sparrow. Animal Behaviour, 32(1), 172-181. https://doi.org/10.1016/S0003-3472(84)80335-8

Bates, D., Mächler, M., Bolker, B., \& Walker, S. (2014). Fitting Linear Mixed-Effects Models using lme4. Retrieved from http://arxiv.org/abs/1406.5823

Beani, L., Briganti, F., Campanella, G., \& LUPO, L. (2000). Effect of androgens on structure and rate 

of crowing in the Japanese quail (Coturnix japonica). Behaviour, 137, 417-435. https://doi.org/10.1163/156853900502150

Bertin, A., \& Richard-Yris, M. A. (2005). Mothering during early development influences subsequent emotional and social behaviour in Japanese quail. Journal of Experimental Zoology Part A: Comparative Experimental Biology, 303(9), 792-801. https://doi.org/10.1002/jez.a.202

Brainard, M. S., \& Doupe, A. J. (2002). What songbirds teach us about learning. Nature, 417(6886), 351-358. https://doi.org/10.1038/417351a

Briefer, E. F. (2012). Vocal expression of emotions in mammals: mechanisms of production and evidence. Journal of Zoology, 288(1), 1-20. https://doi.org/10.1111/j.1469-7998.2012.00920.x

Brittan-Powell, E. F., Dooling, R. J., \& Farabaugh, S. M. (1997). Vocal development in Budgerigars. Journal of Comparative Psychology, 111(3), 226-241. Retrieved from https://s3.amazonaws.com/academia.edu.documents/44800605/Vocal_Development_in_Budgeri gars_Melops20160416-2105018m2u0j.pdf?AWSAccessKeyId=AKIAIWOWYYGZ2Y53UL3A\&Expires=1505494924\&Sign ature=g\%2Fnuu8lCgl\%2Bgbm8dm15aZtHUdCg\%3D\&response-content-disposition=inl

Budde, C. (2001). Ontogeny of calls of a nonpasserine species: The grey crowned crane Balearica regulorum gibbericeps. African Journal of Ecology, 39(1), 33-37. https://doi.org/10.1046/j.13652028.2001.00267.x

Chabert, T., Colin, A., Aubin, T., Shacks, V., Bourquin, S. L., Elsey, R. M., ... Mathevon, N. (2015). Size does matter: crocodile mothers react more to the voice of smaller offspring. Scientific Reports, 5, 15547. https://doi.org/10.1038/srep15547

Chaiken, M. L., Gentner, T. Q., \& Hulse, S. H. (1997). Effects of Social Interaction on the Development of Starling Song and the Perception of These Effects by Conspecifics. Journal of Comparative Psychology, 111(4), 379-392. https://doi.org/10.1037/0735-7036.111.4.379 

songbird: habituation and individual discrimination in superb fairy-wren embryos. Proceedings of the Royal Society B: Biological Sciences, 281(1797), $20141154-20141154$. https://doi.org/10.1098/rspb.2014.1154

Colombelli-Négrel, D., Hauber, M. E., Robertson, J., Sulloway, F. J., Hoi, H., Griggio, M., \& Kleindorfer, S. (2012). Embryonic learning of vocal passwords in superb fairy-wrens reveals intruder cuckoo nestlings. Current Biology, 22(22), 2155-2160. https://doi.org/10.1016/j.cub.2012.09.025

Colombelli-Négrel, D., \& Kleindorfer, S. (2017). Prenatal environment affects embryonic response to song. Biology Letters, 13(8), 20170302. https://doi.org/10.1098/rsbl.2017.0302

de Margerie, E., Peris, A., Pittet, F., Houdelier, C., Lumineau, S., \& Richard-Yris, M. A. (2013). Effect of mothering on the spatial exploratory behavior of quail chicks. Developmental Psychobiology, 55(3), 256-264. https://doi.org/10.1002/dev.21019

Derégnaucourt, S., \& Gahr, M. (2013). Horizontal transmission of the father’s song in the zebra finch (Taeniopygia guttata). Biology Letters, 9(4). https://doi.org/10.1098/rsbl.2013.0247

Derégnaucourt, S., Saar, S., \& Gahr, M. (2009). Dynamics of crowing development in the domestic Japanese quail (Coturnix coturnix japonica). Proceedings of the Royal Society B: Biological Sciences, 276(1665), 2153-2162. https://doi.org/10.1098/rspb.2009.0016

Formanek, L., Richard-Yris, M., Houdelier, C., \& Lumineau, S. (2009). Epigenetic Maternal Effects on Endogenous Rhythms in Precocial Birds. Chronobiology International, 26(3), 396-414. https://doi.org/10.1080/07420520902892433

Fox, J., \& Weisberg, S. (2010). An R Companion to Applied Regression (Google eBook). Retrieved from https://books.google.fr/books?hl=fr\&lr=\&id=uPNrDwAAQBAJ\&oi=fnd\&pg=PP1\&dq=An+\%7 BR\%7D+Companion+to+Applied+Regression\&ots=MvJ6aI9w45\&sig=4GepwYEBR13dSCa1B X8OkWHPgB8 
Guyomarc’h, J. C., \& Guyomarc'h, C. (1996). Vocal communication in European quail, comparison with Japanese quail. Comptes Rendus de l'Academie Des Sciences Série 3 Sciences de La Vie, 319, 827-834. Retrieved from https://hal.archives-ouvertes.fr/hal-01370124/

Jarvis, E. D. (2004). Learned birdsong and the neurobiology of human language. In Annals of the New York Academy of Sciences (Vol. 1016, pp. 749-777). Wiley/Blackwell (10.1111). https://doi.org/10.1196/annals.1298.038

Kleindorfer, S., Evans, C., Hauber, M. E., \& Colombelli-Négrel, D. (2018). Could prenatal sound discrimination predict vocal complexity later in life? BMC Zoology, 3(1), 11. https://doi.org/10.1186/s40850-018-0038-1

Klenova, A. V. (2015). Chick Begging Calls Reflect Degree of Hunger in Three Auk Species (Charadriiformes: Alcidae). PLOS ONE, 10(11), e0140151. https://doi.org/10.1371/journal.pone.0140151

Konishi, M. (1963). The Role of Auditory Feedback in the Vocal Behavior of the Domestic Fowl. Ethology, 20(3), 349-367. https://doi.org/10.1111/J.1439-0310.1963.TB01156.X

Kroodsma, D. E., \& Konishi, M. (1991). A suboscine bird (eastern phoebe, Sayornis phoebe) develops normal song without auditory feedback. Animal Behaviour, 42(3), 477-487. https://doi.org/10.1016/S0003-3472(05)80047-8

Lemasson, A., Gautier, J.-P., \& Hausberger, M. (2003). Vocal similarities and social bonds in Campbell’s monkey (Cercopithecus campbelli). Comptes Rendus Biologies, 326(12), 1185-1193. https://doi.org/10.1016/J.CRVI.2003.10.005

Lemasson, A., Ouattara, K., Petit, E. J., \& Zuberbühler, K. (2011). Social learning of vocal structure in a nonhuman primate? BMC Evolutionary Biology, 11(1). https://doi.org/10.1186/1471-2148-11362

Leonard, M. L., \& Horn, A. G. (2001). Acoustic signalling of hunger and thermal state by nestling tree swallows. Animal Behaviour, 61(1), 87-93. https://doi.org/10.1006/ANBE.2000.1575 
Marler, P., Kreith, M., \& Willis, E. (1962). An analysis of testosterone-induced crowing in young domestic cockerels. Animal Behaviour, 10(1-2), 48-54. https://doi.org/10.1016/00033472(62)90130-6

Marler, Peter, Mundinger, P., Waser, M. S., \& Lutjen, A. (1972). Effects of acoustical stimulation and deprivation on song development in red-winged blackbirds (Agelaius phoeniceus). Animal Behaviour, 20(3), 586-606. https://doi.org/10.1016/S0003-3472(72)80024-1

Miller, P. J. O., \& Bain, D. E. (2000). Within-pod variation in the sound production of a pod of killer whales, Orcinus orca. Animal Behaviour, 60(5), 617-628. https://doi.org/10.1006/anbe.2000.1503

Mills, A. D., Crawford, L. L., Domjan, M., \& Faure, J. M. (1997). The Behavior of the Japanese or Domestic Quail Coturnix japonica. Neuroscience and Biobehavioral Reviews, 21(3), 261-281. https://doi.org/10.1525/auk.2009.07187

Morton, E. S. (1982). Grading, discreteness, redundancy, and motivation-structural rules. Elsevier, $183-212$.

Nottebohm, F., \& Nottebohm, M. E. (1971). Vocalizations and breeding behaviour of surgically deafened ring doves (Streptopelia risoria). Animal Behaviour, 19(2), 313-327. https://doi.org/10.1016/S0003-3472(71)80012-X

Orcutt, F. S. J., \& Orcutt, A. (1976). Nesting and Parental Behavior in Domestic Common Quail. The Auk, 93(1), 135-141. Retrieved from https://www.jstor.org/stable/4084840

Patel, R., Mulder, R. A., \& Cardoso, G. C. (2010). What makes vocalisation frequency an unreliable signal of body size in birds? A study on black swans. Ethology, 116(6), 554-563. https://doi.org/10.1111/j.1439-0310.2010.01769.x

Perez, E. C., Elie, J. E., Soulage, C. O., Soula, H. A., Mathevon, N., \& Vignal, C. (2012). The acoustic expression of stress in a songbird: Does corticosterone drive isolation-induced modifications of zebra finch calls? Hormones and Behavior, 61(4), 573-581. 
Perez, E. C., Mariette, M. M., Cochard, P., Soulage, C. O., Griffith, S. C., \& Vignal, C. (2016). Corticosterone triggers high-pitched nestlings' begging calls and affects parental behavior in the wild zebra finch. Behavioral Ecology, 27(6), arw069. https://doi.org/10.1093/beheco/arw069

Pittet, F., Le Bot, O., Houdelier, C., Richard-Yris, M. A., \& Lumineau, S. (2013). Motherless quail mothers display impaired maternal behavior and produce more fearful and less socially motivated offspring. Developmental Psychobiology, 56(4), 622-634. https://doi.org/10.1002/dev.21129

Poirier, C., Henry, L., Mathelier, M., Lumineau, S., Cousillas, H., \& Hausberger, M. (2004). Direct social contacts override auditory information in the song-learning process in starlings (Sturnus vulgaris). Journal of Comparative Psychology, 118(2), 179-193. https://doi.org/10.1037/07357036.118.2.179

Price, P. H. (1979). Developmental Determinants of Structure in Zebra Finch Song. Journal of Comparative and Physiological Psychology, 93(2), 260-277. Retrieved from http://content.ebscohost.com/ContentServer.asp?EbscoContent=dGJyMNXb4kSeqLA4y9fwOL Cmr0\%2BeprJSs6a4TbGWxWXS\&ContentCustomer=dGJyMOzpsE2xqK5IuePfgeyx9Yvf5ucA $\& \mathrm{~T}=\mathrm{P} \& \mathrm{P}=\mathrm{AN} \& \mathrm{~S}=\mathrm{L} \& \mathrm{D}=\mathrm{pdh} \& \mathrm{~K}=1980-22754-001$

R Core Team. (2016). R: A Language and Environment for Statistical Computing. R Foundation for Statistical Computing, 1(2.11.1), 409. https://doi.org/10.1007/978-3-540-74686-7

Richard-Yris, M.-A., Michel, N., \& Bertin, A. (2005). Nongenomic inheritance of emotional reactivity in Japanese quail. Developmental Psychobiology, 46(1), 1-12. https://doi.org/10.1002/dev.20040

Richard, J. P. (1991). Sound analysis and synthesis using an amiga micro-computer. Bioacoustics, 3(1), 45-60. https://doi.org/10.1080/09524622.1991.9753156

Ripley, B., Venables, B., Bates, D. M., Hornik, K., Gebhardt, A., \& Firth, D. (2018). Package “MASS.” CRAN R-Project. https://doi.org/ISBN 0-387-95457-0 
Riters, L. V. (2012). The role of motivation and reward neural systems in vocal communication in songbirds. Frontiers in Neuroendocrinology. https://doi.org/10.1016/j.yfrne.2012.04.002

Rotella, J. J., \& Ratti, J. T. (1988). Seasonal Variation in Gray Partridge Vocal Behavior. The Condor, 90(2), 304-310. https://doi.org/10.2307/1368558

Takahashi, D. Y., Fenley, A. R., Teramoto, Y., Narayanan, D. Z., Borjon, J. I., Holmes, P., \& Ghazanfar, A. A. (2015). The developmental dynamics of marmoset monkey vocal production. Science, 349(6249), 734-738. https://doi.org/10.1126/science.aab1058

Tchernichovski, O., Lints, T. J., Derégnaucourt, S., Cimenser, A., \& Mitra, P. P. (2004). Studying the song development process: Rationale and methods. In Annals of the New York Academy of Sciences (Vol. 1016, pp. 348-363). Blackwell Publishing Ltd. https://doi.org/10.1196/annals.1298.031

Thorpe, W. H. (1958). The learning of song patterns by birds, with especial reference to the song of the Chaffinch Fringilla Coelebs. Ibis, 100(4), 535-570. https://doi.org/10.1111/j.1474919X.1958.tb07960.x

Volman, S. F., \& Khanna, H. (1995). Convergence of untutored song in group-reared zebra finches (Taeniopygia guttata). Journal of Comparative Psychology (Washington, D.C. : 1983), 109(3), 211-221. Retrieved from http://www.ncbi.nlm.nih.gov/pubmed/7554823

Walcott, C., Mager, J. N., \& Piper, W. (2006). Changing territories, changing tunes: Male loons, Gavia immer, change their vocalizations when they change territories. Animal Behaviour, 71(3), 673-683. https://doi.org/10.1016/j.anbehav.2005.07.011

Zhang, Y. S., \& Ghazanfar, A. A. (2016). Perinatally Influenced Autonomic System Fluctuations Drive Infant Vocal Sequences. Current Biology, 26(10), 1249-1260. https://doi.org/10.1016/J.CUB.2016.03.023 
532 Table 1. Description of the acoustic parameters used to compare the vocal development of

533 mothered and non-mothered chicks.

\begin{tabular}{|c|c|c|c|}
\hline Acoustic parameters & Description & Rally calls & Contact calls \\
\hline Duration (ms) & Time from the beginning to the end of the call & $\checkmark$ & $\checkmark$ \\
\hline Frequency modulation & Mean slope of the call frequency & $\checkmark$ & \\
\hline Mean frequency $(\mathrm{Hz})$ & Center of power distribution & $\checkmark$ & \\
\hline Wiener entropy & $\begin{array}{l}\text { Spectral flatness based on the ratio of geometric } \\
\text { mean to arithmetic mean of the spectrum }\end{array}$ & & \\
\hline Maximum frequency (Hz) & The highest frequency value in the call & & $\checkmark$ \\
\hline Frequency bandwidth (Hz) & $\begin{array}{l}\text { Difference between the maximum and the } \\
\text { minimum frequency }\end{array}$ & & $\checkmark$ \\
\hline
\end{tabular}

534

535

536

537

538

539

540

541

542

543

544

545

546 
Table 2. Statistical analysis of developmental changes for rally calls and contact calls.

Acoustical parameter $\sim$ Group+ Sex+ Postnatal day+ Postnatal day:Group+ Postnatal day:Sex+ Group:Sex+ (1|Bird ID)+ (1|Pair ID)+ (1|Pair composition)

\begin{tabular}{|c|c|c|c|c|c|c|c|c|c|c|c|c|}
\hline \multirow{2}{*}{$\begin{array}{l}\text { Rally calls } \\
\text { Explanatory variables }\end{array}$} & \multicolumn{3}{|c|}{ Call duration } & \multicolumn{3}{|c|}{ Frequency modulation } & \multicolumn{3}{|c|}{ Mean frequency } & \multicolumn{3}{|c|}{ Wiener entropy } \\
\hline & $\chi^{2}$ & $d f$ & p-value & $\chi^{2}$ & $d f$ & p-value & $\chi^{2}$ & $d f$ & $p$-value & $\chi^{2}$ & $d f$ & $p$-value \\
\hline Group & 2.37 & 1 & 0.12 & 2.06 & 1 & 0.15 & 2.46 & 1 & 0.12 & 0.37 & 1 & 0.54 \\
\hline Sex & 0.67 & 1 & 0.41 & 5.82 & 1 & 0.02 & 5.75 & 1 & 0.02 & 1.4 & 1 & 0.24 \\
\hline Postnatal day & 23.65 & 1 & $<0.0001$ & 10835.47 & 1 & $<0.0001$ & 28658.25 & 1 & $<0.0001$ & 4035.48 & 1 & $<0.0001$ \\
\hline Group*Postnatal day & 27.68 & 1 & $<0.0001$ & 20.04 & 1 & $<0.0001$ & 88.24 & 1 & $<0.0001$ & 159.55 & 1 & $<0.0001$ \\
\hline Sex*Postnatal day & 93.84 & 1 & $<0.0001$ & 0.14 & 1 & 0.71 & 72.75 & 1 & $<0.0001$ & 3.07 & 1 & 0.08 \\
\hline Group*Sex & 0.07 & 1 & 0.79 & 0.14 & 1 & 0.71 & 0.05 & 1 & 0.82 & 0.04 & 1 & 0.83 \\
\hline
\end{tabular}

Acoustical parameter Group+ Sex+ Postnatal day+ Postnatal day:Group+ Postnatal day:Sex+ Group:Sex+ (1|Bird ID)+ (1|Pair ID)+ (1|Pair composition)

\begin{tabular}{|c|c|c|c|c|c|c|c|c|c|c|c|c|}
\hline \multirow{2}{*}{$\begin{array}{l}\text { Contact calls } \\
\text { Explanatory variables }\end{array}$} & \multicolumn{3}{|c|}{ Call duration } & \multicolumn{3}{|c|}{ Frequency bandwidth } & \multicolumn{3}{|c|}{ Maximal frequency } & \multicolumn{3}{|c|}{ Acoustical similarity } \\
\hline & $\chi^{2}$ & $d f$ & p-value & $\chi^{2}$ & $d f$ & $p$-value & $\chi^{2}$ & $d f$ & $p$-value & $\chi^{2}$ & $d f$ & p-value \\
\hline Group & 1.27 & 1 & 0.26 & 2.15 & 1 & 0.14 & 0.24 & 1 & 0.62 & 2.03 & 1 & 0.15 \\
\hline Sex & 2.85 & 1 & 0.09 & 3.28 & 1 & 0.07 & 0.08 & 1 & 0.77 & 1.35 & 1 & 0.24 \\
\hline Postnatal day & 23.28 & 1 & $<0.0001$ & 51.42 & 1 & $<0.0001$ & 956.45 & 1 & $<0.0001$ & 14.92 & 1 & 0.0001 \\
\hline Comparison level & - & - & - & & - & - & - & - & - & 114.11 & 1 & $<0.0001$ \\
\hline Group*Postnatal day & 12.53 & 1 & 0.0004 & 5.86 & 1 & 0.02 & 14.27 & 1 & 0.0002 & 1.91 & 1 & 0.17 \\
\hline Sex*Postnatal day & 4.47 & 1 & 0.04 & 15.67 & 1 & $<0.0001$ & 6.72 & 1 & 0.01 & 7.47 & 1 & 0.006 \\
\hline Group*Sex & 0.31 & 1 & 0.58 & 0.4 & 1 & 0.52 & 1.17 & 1 & 0.28 & 0.45 & 1 & 0.5 \\
\hline Comparison level*Postnatal day & - & & & - & - & - & - & - & - & 5.79 & 1 & 0.02 \\
\hline Group*Comparison level & & & - & - & - & - & - & - & - & 0.2 & 1 & 0.65 \\
\hline Sex*Comparison level & & & - & - & - & - & - & - & - & 0.37 & 1 & 0.54 \\
\hline
\end{tabular}

548 Significant results (linear models, $p<0.05$ ) are in bold. (-) for factors not included in the statistical model. 


\section{Mothered chick}
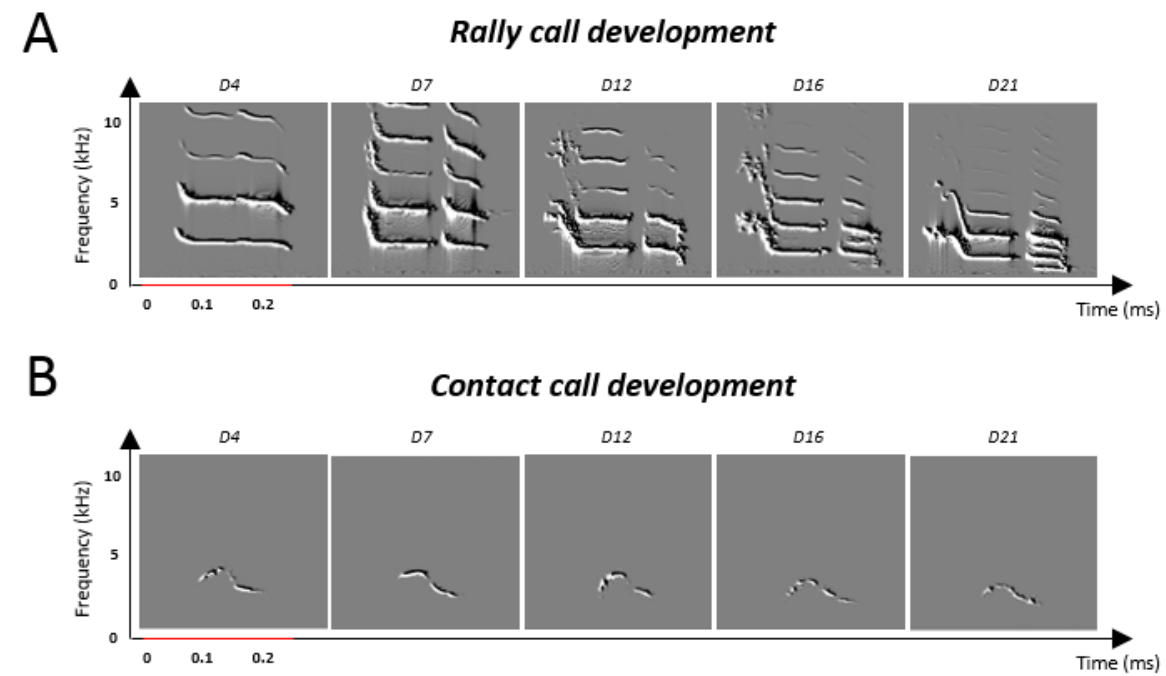

Non-Mothered chick

C Rally call development

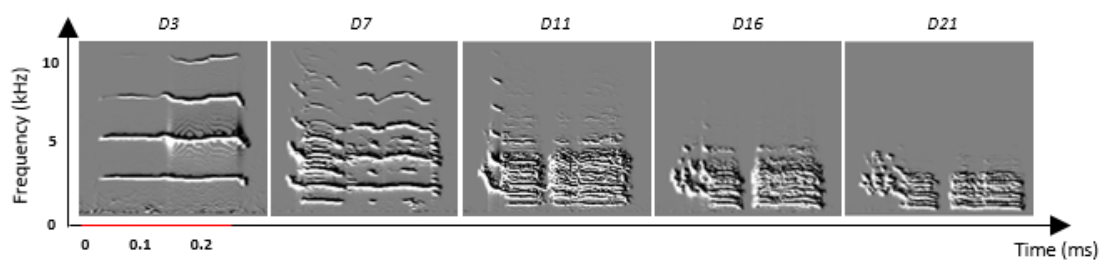

D

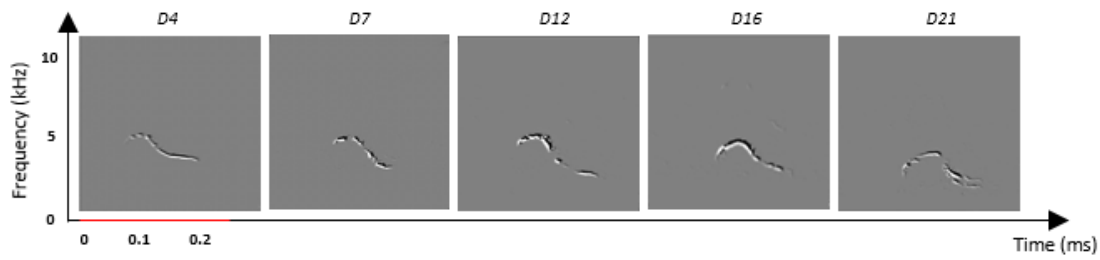

Figure 1. Vocal development on different days of the rally call $(\mathrm{A}, \mathrm{C})$

and the contact call $(B, D)$ of a mothered and a non-mothered chick.

552 Figure 1. Vocal development on different days of the rally call (A) and the contact call (B) of a mothered chick. 

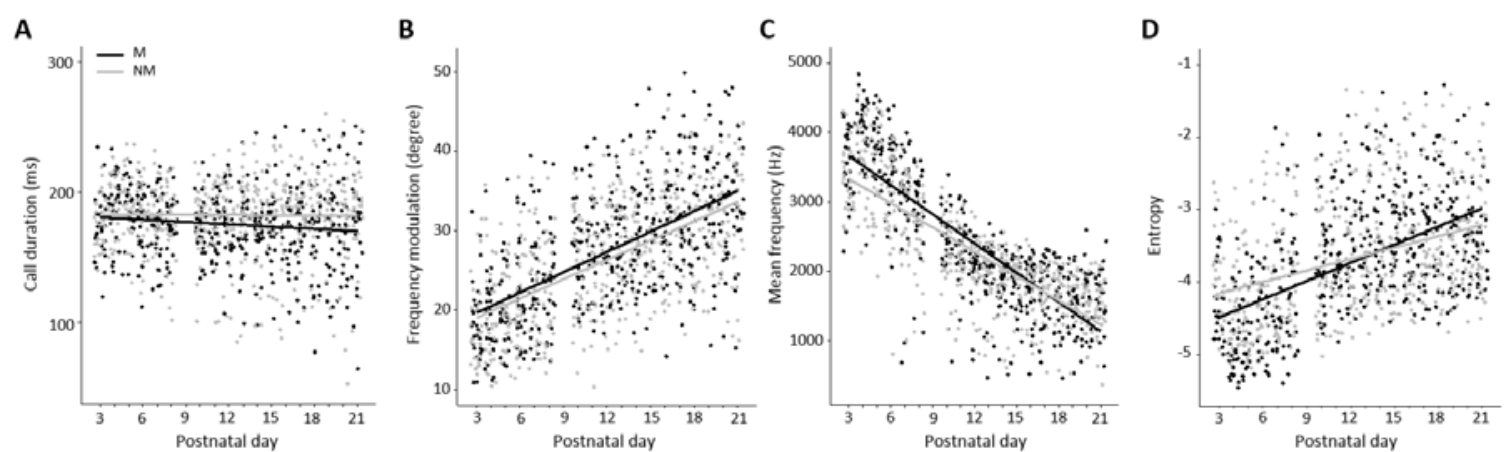

Figure 2. (A-D) Acoustic changes of rally calls along the development of mothered (M) and nonmeans for each day. Trend curves are linear regressions.

559

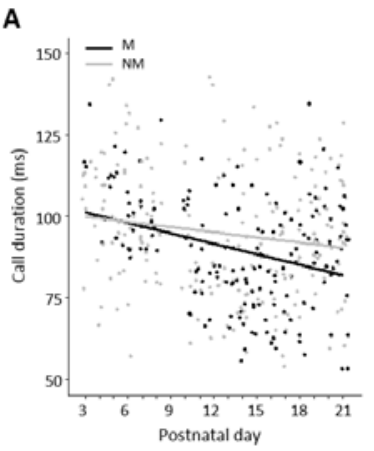

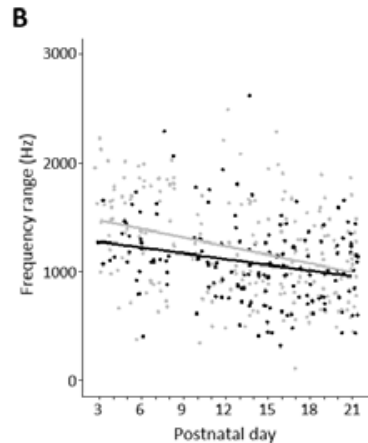

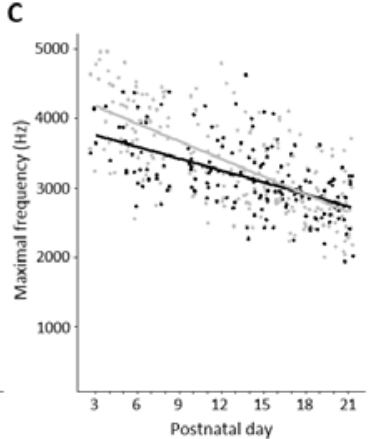

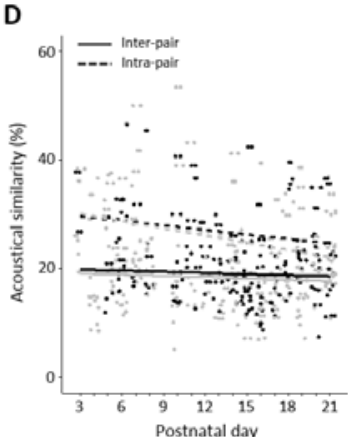

560

561

562

563

564

Figure 3. (A-C) Acoustic changes of contact calls during the development of mothered (M) and non-mothered (NM) chicks, from postnatal day 3 to postnatal day 21. (A) Call duration (ms); (B) Frequency bandwidth (Hz); (C) Maximal frequency (Hz). Dots represent individual means for each day. (D) Developmental changes of the percentage of intra- (dotted lines, filled dots) and inter-pair (full lines, open dots) acoustical similarity. Trend curves are linear regressions. 
A

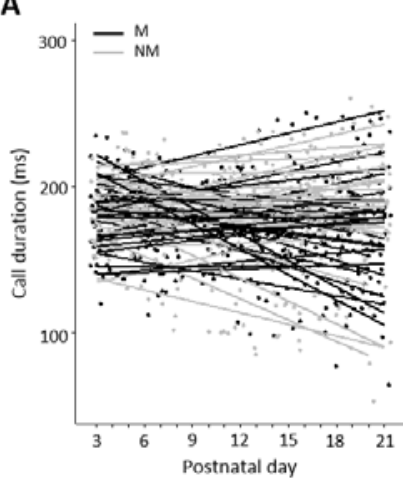

B

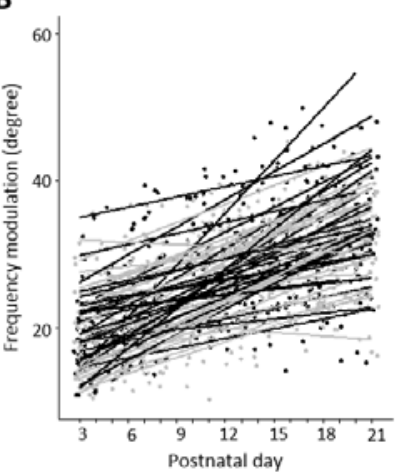

C

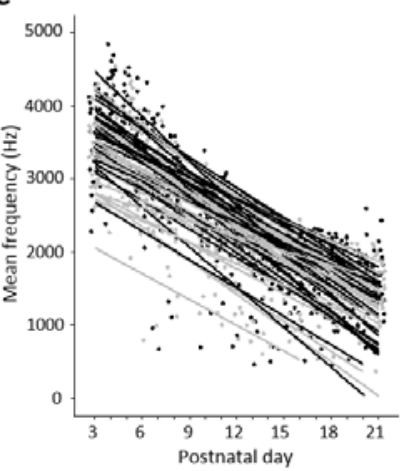

D

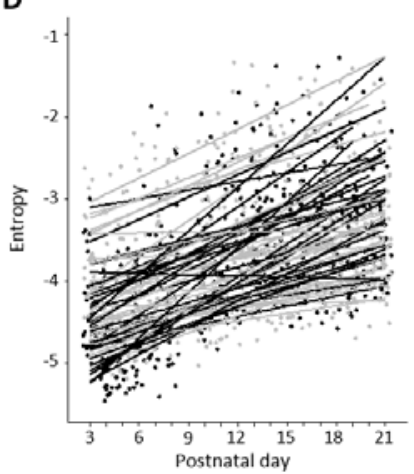

Figure S1. (A-D) Acoustic changes of rally calls along the development of mothered (M) and nonmothered (NM) chicks, from postnatal day 3 to postnatal day 21. (A) Call duration (ms); (B) Frequency Modulation; (C) Mean frequency (Hz); (D) Wiener Entropy. Dots represent individual means for each day. Trend curves are linear regressions by individuals.

5

6

7
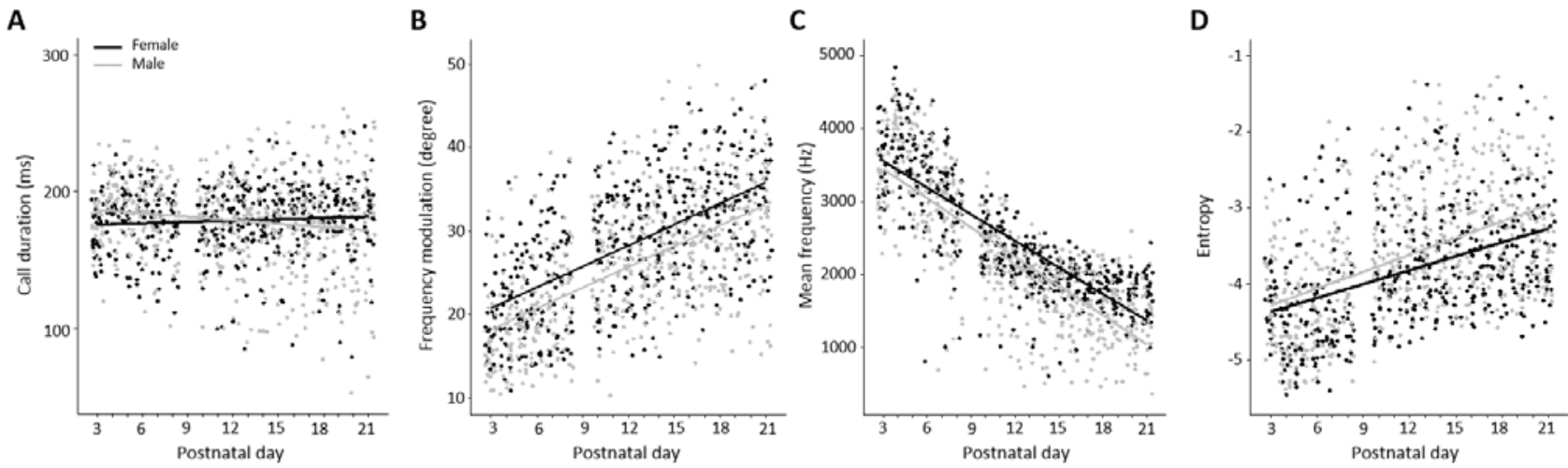

Figure S2. (A-D) Sex effects on the acoustical changes of rally calls during development, from postnatal day 3 to postnatal day 21. (A) Call duration (ms); (B) Frequency Modulation; (C) Mean frequency (Hz); (D) Wiener entropy. Dots represent individual means for each day. Trend curves are linear regressions. 


\section{Supplementary methods}

A

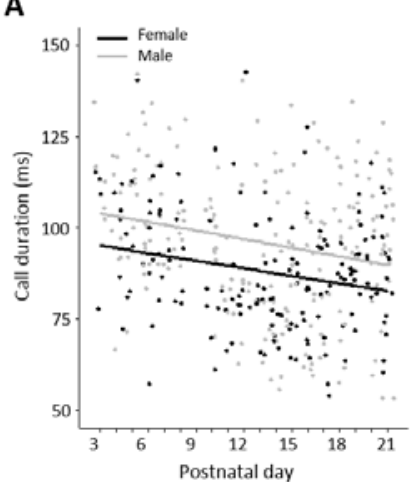

B

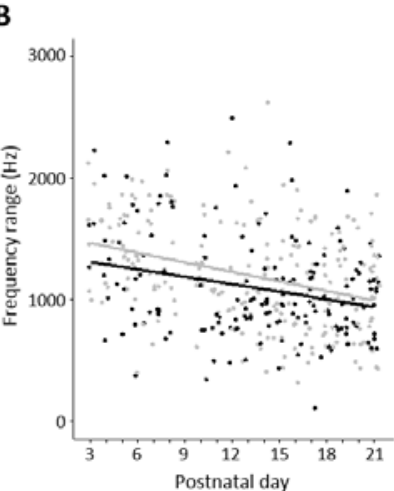

c

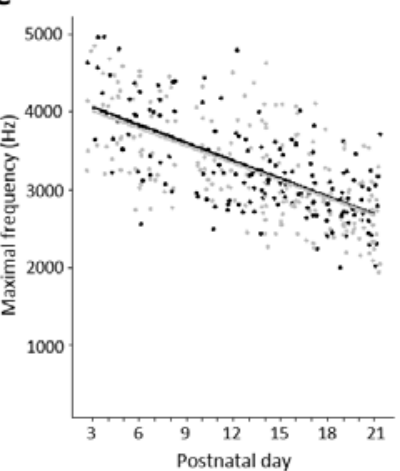

D

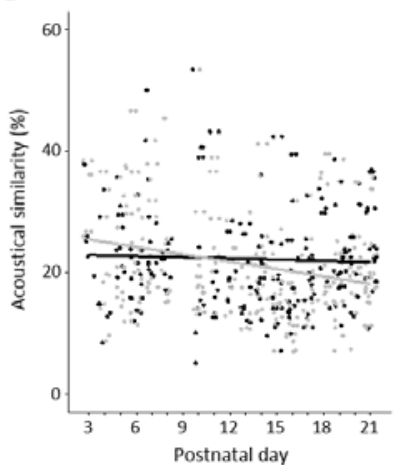

13

14

15

16

17

18

19

20

21

Figure S3. (A-C) Sex effects on the acoustical changes of contact calls during development, from postnatal day 3 to postnatal day 21. (A) Call duration (ms); (B) Frequency bandwidth ( $\mathrm{Hz}$ ); (C) Maximal frequency $(\mathrm{Hz})$. Dots represent individual means for each day. (D) Developmental changes of the percentage of intra- (dotted lines) and inter-pair (full lines) acoustical similarity. Trend curves are linear regressions.

\section{D25.}

Table S1. Body weights (mean \pm standard error) of mothered and non-mothered chicks from D1 to

\begin{tabular}{lcc}
\hline & Mothered & Non-mothered \\
\hline Postnatal days & $10.44 \pm 0.1273$ & \\
\hline D1 & $54.86 \pm 2.1350$ & $10.10 \pm 0.1194$ \\
D11 & $108.87 \pm 3.2251$ & $63.40 \pm 1.5140$ \\
D18 & $176.70 \pm 4.3211$ & $120.07 \pm 2.1490$ \\
D25 &
\end{tabular}


Supplementary methods

Table S2. Influence of the mothering on the acoustical changes of the rally calls and the contact calls during chicks' vocal development.

Acoustical parameter Group+ Sex+ Postnatal day+ Postnatal day:Group+ Postnatal day:Sex+ Group:Sex+ (1|Bird ID)+ (1|Pair ID)+ (1|Pair composition)

\begin{tabular}{|c|c|c|c|c|c|c|c|c|c|c|c|c|}
\hline \multirow{2}{*}{$\frac{\text { Rally calls }}{\text { Fixed Effects }}$} & \multicolumn{3}{|c|}{ Call duration } & \multicolumn{3}{|c|}{ Frequency modulation } & \multicolumn{3}{|c|}{ Mean frequency (sqrt) } & \multicolumn{3}{|c|}{ Wiener entropy } \\
\hline & Estimate & Std.Error & t-value & Estimate & Std.Error & t-value & Estimate & Std.Error & t-value & Estimate & Std.Error & t-value \\
\hline (Intercept) & 175.13 & 6.52 & 26.87 & 29.04 & 1.51 & 19.24 & 49.97 & 1.38 & 36.29 & -3.85 & 0.17 & -22.11 \\
\hline Group - NM & 6.88 & 8.21 & 0.84 & -1.28 & 1.86 & -0.69 & -2.16 & 1.75 & -1.24 & 0.06 & 0.22 & 0.27 \\
\hline Sex-male & 2.78 & 7.98 & 0.35 & -2.51 & 1.81 & -1.38 & -3.01 & 1.64 & -1.83 & 0.13 & 0.2 & 0.67 \\
\hline Postnatal day & 0.04 & 0.45 & 0.1 & 4.94 & 0.09 & 54.06 & -7.36 & 0.09 & -84.68 & 0.45 & 0.01 & 37.48 \\
\hline Group - NM*Postnatal day & 2.44 & 0.47 & 5.26 & -0.42 & 0.09 & -4.48 & 0.84 & 0.09 & 9.39 & -0.16 & 0.01 & -12.63 \\
\hline Sex - male*Postnatal day & -4.51 & 0.47 & -9.69 & 0.04 & 0.1 & 0.37 & -0.77 & 0.09 & -8.53 & 0.02 & 0.01 & 1.75 \\
\hline Group - NM*Sex-male & 2.97 & 11.02 & 0.27 & -0.92 & 2.5 & -0.37 & 0.52 & 2.26 & 0.23 & 0.06 & 0.28 & 0.21 \\
\hline
\end{tabular}

Acoustical parameter Group+ Sex+ Postnatal day+ Postnatal day:Group+ Postnatal day:Sex+ Group:Sex+ (1|Bird ID)+ (1|Pair ID)+ (1|Pair composition)

Acoustical similarity Group+ Sex+ Postnatal day+ Comparison level+ Postnatal day:Group+ Postnatal day:Sex+ Group:Sex+ Comparison level:Postnatal day+ Group:Comparison level+

Sex:Comparison level+ (1|Bird ID)+ (1|Pair ID)+ (1| Pair composition)

\begin{tabular}{|c|c|c|c|c|c|c|c|c|c|c|c|c|}
\hline \multirow{2}{*}{$\begin{array}{l}\text { Contact calls } \\
\text { Fixed Effects }\end{array}$} & \multicolumn{3}{|c|}{ Call duration } & \multicolumn{3}{|c|}{ Frequency bandwidth } & \multicolumn{3}{|c|}{ Maximal frequency } & \multicolumn{3}{|c|}{ Acoustical similarity } \\
\hline & Estimate & Std.Error & t-value & Estimate & Std.Error & t-value & Estimate & Std.Error & t-value & Estimate & Std.Error & t-value \\
\hline (Intercept) & 86.99 & 4.14 & 21.03 & 978.58 & 107.03 & 9.14 & 3083.08 & 150.51 & 20.48 & -1.61 & 0.16 & -10.2 \\
\hline Group - NM & 2.4 & 5.35 & 0.45 & 100.3 & 123.19 & 0.81 & 166.03 & 151.99 & 1.09 & 0.13 & 0.14 & 0.95 \\
\hline Sex-male & 2.96 & 4.2 & 0.71 & 76.29 & 101.44 & 0.75 & 66.54 & 102.45 & 0.65 & 0.27 & 0.14 & 2.002 \\
\hline Postnatal day & -3.5 & 1.01 & -3.46 & 11.75 & 24.62 & 0.48 & -260.38 & 24.64 & -10.57 & 0.01 & 0.009 & 1.44 \\
\hline Comparison level - intra & - & & & - & - & - & - & - & - & 0.69 & 0.13 & 5.24 \\
\hline Group - NM*Postnatal day & 3.59 & 1.01 & 3.54 & -59.58 & 24.62 & -2.42 & -93.29 & 24.69 & -3.78 & -0.01 & 0.008 & -1.37 \\
\hline Sex - male*Postnatal day & -2.04 & 0.97 & -2.11 & -93.09 & 23.5 & -3.96 & -60.98 & 23.52 & -2.59 & -0.01 & 0.007 & -2.71 \\
\hline Group - NM*Sex-male & 3.12 & 5.57 & 0.56 & 85.68 & 134.64 & 0.64 & -146.47 & 135.21 & -1.08 & -0.06 & 0.09 & -0.66 \\
\hline Comparison level - intra*Postnatal day & & - & - & - & - & - & - & - & - & -0.02 & 0.007 & -2.38 \\
\hline Group*Comparison level - intra pairs & & - & - & - & - & - & - & - & - & -0.04 & 0.08 & -0.44 \\
\hline Sex*Comparison level - intra pairs & - & - & - & - & - & - & - & - & - & -0.05 & 0.08 & -0.6 \\
\hline
\end{tabular}




\section{Supplementary methods}

Table S3. Influence of the mothering on the acoustical changes of the rally calls and the contact calls during chicks' vocal development. Slopes estimates for group, sex and comparison level's effects.

\begin{tabular}{|c|c|c|c|c|c|c|c|}
\hline & Estimate & Std.Error & $d f$ & lower.CL & upper.CL & t.ratio & $p$-value \\
\hline \multicolumn{8}{|l|}{ Rally calls } \\
\hline \multicolumn{8}{|c|}{ Call duration } \\
\hline $\mathrm{M}$ & -0.4 & 0.06 & 27409.59 & -0.52 & -0.28 & -6.63 & $<0.0001$ \\
\hline NM & 0.04 & 0.06 & 27417.59 & -0.07 & 0.16 & 0.75 & 0.45 \\
\hline Female & 0.23 & 0.06 & 27412.76 & 0.11 & 0.35 & 3.76 & 0.0002 \\
\hline Male & -0.59 & 0.06 & 27414.62 & -0.7 & -0.48 & -10.46 & $<0.0001$ \\
\hline \multicolumn{8}{|c|}{ Frequency modulation } \\
\hline $\mathrm{M}$ & 0.9 & 0.01 & 27408.1 & 0.88 & 0.93 & 73.16 & $<0.0001$ \\
\hline NM & 0.83 & 0.01 & 27414.74 & 0.8 & 0.85 & 71.31 & $<0.0001$ \\
\hline Female & 0.86 & 0.01 & 27410.71 & 0.84 & 0.89 & 69.11 & $<0.0001$ \\
\hline Male & 0.87 & 0.01 & 27412.26 & 0.85 & 0.89 & 75.63 & $<0.0001$ \\
\hline \multicolumn{8}{|c|}{ Mean frequency (sqrt) } \\
\hline M & -1.41 & 0.01 & 27408.45 & -1.44 & -1.39 & -120.14 & $<0.0001$ \\
\hline NM & -1.26 & 0.01 & 27415.19 & -1.28 & -1.24 & -114.06 & $<0.0001$ \\
\hline Female & -1.27 & 0.01 & 27411.34 & -1.29 & -1.24 & -106.61 & $<0.0001$ \\
\hline Male & -1.41 & 0.01 & 27412.92 & -1.43 & -1.38 & -128.61 & $<0.0001$ \\
\hline \multicolumn{8}{|c|}{ Wiener entropy } \\
\hline M & 0.09 & 0.002 & 27410.52 & 0.08 & 0.09 & 51.77 & $<0.0001$ \\
\hline NM & 0.06 & 0.002 & 27418.42 & 0.05 & 0.06 & 36.41 & $<0.0001$ \\
\hline Female & 0.07 & 0.002 & 27414.16 & 0.07 & 0.07 & 41.35 & $<0.0001$ \\
\hline Male & 0.07 & 0.003 & 37416.03 & 0.07 & 0.08 & 47.54 & $<0.0001$ \\
\hline \multicolumn{8}{|c|}{ Contact calls } \\
\hline \multicolumn{8}{|c|}{ Call duration } \\
\hline M & -0.85 & 0.16 & 1328.01 & -1.16 & -0.54 & -5.4 & $<0.0001$ \\
\hline NM & -0.18 & 0.11 & 1324.01 & -0.39 & 0.04 & -1.58 & 0.11 \\
\hline Female & -0.32 & 0.14 & 1318.21 & -0.6 & -0.04 & -2.22 & 0.03 \\
\hline Male & -0.7 & 0.12 & 1328.49 & -0.94 & -0.47 & -5.82 & $<0.0001$ \\
\hline \multicolumn{8}{|c|}{ Frequency bandwidth } \\
\hline $\mathrm{M}$ & -6.53 & 3.82 & 1326.54 & -14.01 & 0.96 & -1.71 & 0.09 \\
\hline NM & -17.7 & 2.69 & 1325.59 & -22.98 & -12.43 & -6.59 & $<0.0001$ \\
\hline Female & -3.38 & 3.51 & 1323.25 & -10.26 & 3.49 & -0.97 & 0.34 \\
\hline Male & -20.85 & 2.93 & 1327.58 & -26.6 & -15.09 & -7.11 & $<0.0001$ \\
\hline \multicolumn{8}{|c|}{ Maximal frequency } \\
\hline M & -54.56 & 3.83 & 1325.55 & -62.07 & -47.05 & -14.26 & $<0.0001$ \\
\hline NM & -72.06 & 2.69 & 1318.85 & -77.34 & -66.78 & -26.79 & $<0.0001$ \\
\hline Female & -57.59 & 3.5 & 1316.29 & -64.46 & -50.72 & -16.45 & $<0.0001$ \\
\hline Male & -69.03 & 2.94 & 1324.89 & -74.8 & -63.26 & -23.47 & $<0.0001$ \\
\hline \multicolumn{8}{|c|}{ Acoustical similarity } \\
\hline M & -0.006 & 0.006 & 457 & -0.02 & 0.006 & -0.98 & 0.33 \\
\hline NM & -0.02 & 0.005 & 457 & -0.03 & -0.008 & -3.66 & 0.0003 \\
\hline Female & -0.001 & 0.006 & 457 & -0.01 & 0.01 & -0.21 & 0.83 \\
\hline Male & -0.02 & 0.005 & 457 & -0.03 & -0.01 & -4.37 & $<0.0001$ \\
\hline Inter-pair & -0.003 & 0.005 & 457 & -0.01 & 0.008 & -0.5 & 0.62 \\
\hline Intra-pair & -0.02 & 0.005 & 457 & -0.03 & -0.009 & -3.74 & 0.0002 \\
\hline
\end{tabular}

Linear mixed models were applied on acoustical parameters of both rally calls and contact calls (Imer function from Ime4 $R$ package). A generalized mixed model was applied on the similarity index of the contact calls (gImmPQL function from MASS $R$ package). Results were obtained with the emtrends function of $R$ (from emmeans package). 